\title{
Novel Biomarkers and the Diagnosis of Prion Diseases
}

\section{Saima Zafar*, Neelam Younus and Inga Zerr}

Department of Neurology, Clinical Dementia Center and DZNE, Georg-August University, University Medical Center Goettingen (UMG), Robert-Koch-Str. 40, 37075, Goettingen, Germany

\begin{abstract}
In fatal neurodegenerative diseases, prion diseases have high risk of transmission ability and no cure and effective treatment. This abnormal folded protein disease in brain pose a serious threat to public health and the development of early diagnostic markers and new therapeutic approaches is in pronounced plea. Prion disease show infectious and incurable irrepressible nature and long period of silent incubations and nature of prion diseases, development of early diagnostic markers is in great demand to prevent a potential spread of the disease and for early diagnosis of the disease given the long incubation periods of disease. Moreover discovery of novel biomarkers can lead to development of new therapeutic targets and better understanding of the underlying pathogenesis of the Prion diseases.
\end{abstract}

Keywords: Biomarkers; Novel; PrP; Proteome; Interactome; CSF; Exosome; RT-QuIC; TAU, Blood

\section{Prion Diseases}

Prion diseases or transmissible spongiform encephalopathies (TSEs) are included in neurodegenerative diseases, which are rare and fatal for both humans and animals [1]. Prions or "Proteinaceous infectious particle" are known to be the result of conversion of the cellular normal prion protein form $\left(\mathrm{PrP}^{\mathrm{C}}\right)$ into its diseased aggregationprone form called as prion $\left(\mathrm{PrP}^{\mathrm{sc}}\right)$ [2-5]. The only exact diagnosis is possible only after post mortem. The both diseased $\mathrm{PrP}^{\mathrm{Sc}}$ and normal cellular $\operatorname{PrP}^{\mathrm{C}}$ form consists of same amino acid sequence, but secondary, tertiary, and quaternary structures are differ [6-8]. Furthermore, different fragments of $\operatorname{PrP}^{\mathrm{C}}$ as well as $\mathrm{PrP}^{\mathrm{sc}}$ can be found in various lengths [9-13] and the targeted detection could demonstrate difficulty in view of the complex biochemical nature. The normal function of these prion protein forms $\left(\mathrm{PrP}^{\mathrm{C}} / \mathrm{PrP}^{\mathrm{Sc}}\right)$ are still not clear but there are some reports on the predictive role of $(\mathrm{PrP})$ in the brain functions i.e. pro- and anti- inflammatory role [14-18], protection of mice in lipopolysaccharide induced infection in mice infection by regulating the process of inflammatory response [18].

\section{Diagnosis of Prion Diseases}

The usual way of prion diagnosis is by the clinical parameters and further confirmation with histopathological examination of brain tissue after post-mortem brain tissue. The reliable diagnosis of prion diseases relies on the ability to detect the pathological isoform of the host protein $\operatorname{PrP}^{\mathrm{c}}\left(\mathrm{PrP}^{\mathrm{sc}}\right)[19,20]$. Immunological detection of $\mathrm{PrP}^{\mathrm{sc}}$ is sensitive and specific enough for postmortem testing of brain tissues; however, this is not the case for readily accessible body fluids or for the detection of recently identified novel prions with unique biochemical properties due to low concentration of $\mathrm{PrP}^{\mathrm{Sc}}$ [21-23]. Several diagnostic kits are commercially available for the immunochemical detection of $\mathrm{PrP}^{\mathrm{Sc}}$ in the post-mortem brain tissues.

Recent report demonstrated that the $83 \%$ of cases SCJD striatum and/or cortical regions of the brain showed high signal intensity in the fluid attenuated inversion recovery (FLAIR) and in the diffusionweighted imaging (DWI) sequences [24]. Furthermore, for the specific and rapid diagnosis of sCJD real-time quaking-Induced conversion analysis (RT-QuIC) also a novel method for the ante-mortem diagnosis of human prion diseases [25-28].

To keep the human food chain clear, some quick screening tests are also available for the infected cattle. But still in live animals or humans still there is a lack of detection of prion diseases. Novel approaches are under progress in body fluids, intended to increase sensitivity and specificity of $\mathrm{PrP}^{\mathrm{Sc}}$ detection. In this report, we review the classical biomarkers as well as the possibility of novel biomarker discovery in prion diseases.

\section{CSF Biomarkers}

CSF proteome alterations reflect pathological changes in the brain, and could possibly be able to provide an early diagnostic tool in prion diseases. There are many protein based biomarkers in cerebrospinal fluid (CSF) that are used for diagnosis of human prion diseases. Frequently used biomarker proteins are 14-3-3, tau, phospho-tau/tau ratio, S100, and the neuron-specific enolase (Figure 1) [29-34]. The combination of elevated T-tau levels and increased T-tau/P-tau ratios in CJD patients has a very high sensitivity and specificity in comparasion to differential diagnoses CJD [35,36]. A very recent study has described tau as a biomarker of neuronal damage with a significant negative correlation between CSF tau levels and the cognitive performance of the patients [37]. In addition, a significant positive correlation between tau levels and the clinical disease severity has been reported. This disease progression rate suggesting the notion that tau levels reflects the extent of neuronal damage, at least before the end stage of the disease $[37,38]$. Previously, an inverse correlation of CSF tau level to the disease duration has been reported but not with the disease progression stage [39]. Induced expressional levels of other neurodegenerative-related proteins such as beta-amyloid [27,40-42] and alpha-synuclein $[37,43]$ have also been reported in the CSF of patients with sporadic CJD when compared to control samples. These CSF biomarkers have proven to be an extremely valuable in the confirmatory diagnosis of CJD cases. However, all the known biomarkers are sensitive only when the disease

*Corresponding author: Saima Zafar, Department of Neurology,Clinical Dementia Center and DZNE, University Medical Centre Goettingen, 37075, Goettingen, Germany. Tel: 0049-551-39-14962; E-mail: sz_awaan@yahoo.com, saima.zafar@ med.uni-goettingen.de

Received September 30, 2015; Accepted November 23, 2015; Published November 26, 2015

Citation: Zafar S, Younus N, Zerr I (2015) Novel Biomarkers and the Diagnosis of Prion Diseases. J Mol Biomarkers Diagn S8:011. doi:10.4172/2155-9929.S8-011

Copyright: ( 2015 Zafar S, et al. This is an open-access article distributed under the terms of the Creative Commons Attribution License, which permits unrestricted use, distribution, and reproduction in any medium, provided the original author and source are credited 


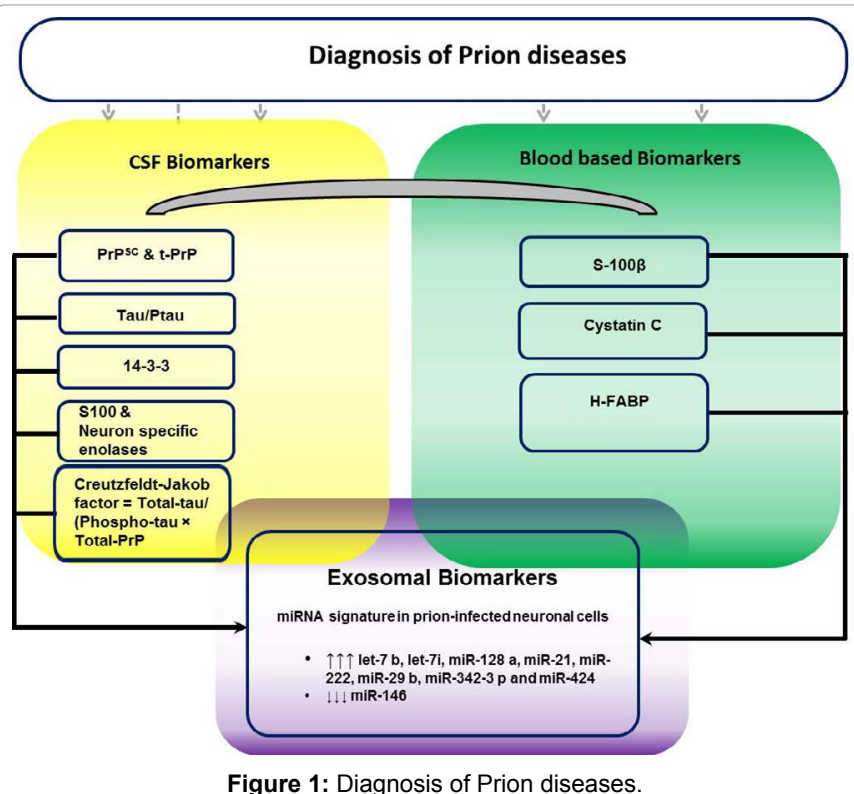

is already at an advanced or terminal stage and there is no data available at preclinical stages of the prion disease.

In recent years, total $\operatorname{PrP}(\mathrm{t}-\mathrm{PrP})$ level in CSF have been described as a new biomarker [44]. The specificity of ( $t$-PrP) level could help the clinicians for differential diagnosis of atypical cases and profile ambiguity in between the CJD and Alzheimer diseases. Furthermore, the ratio of CSF t-PrP with tau proteins (Creutzfeldt-Jakob factor=Totaltau/ (Phospho-tau $\times$ Total-PrP) lead to differentiate CJD and atypical AD with $100 \%$ sensitivity and $95.7 \%$ specificity [44]. Previously we also reported differential regulatory response of PrP in CJD, Alzheimer disease, Parkinson disease, and dementia with Lewy Bodies disease and found slightly but significant decrease in comparison to age matched controls [45]. Another study also had shown decreased PrP levels in CSF of diseased patients as compared to control [46]. In CJD subtype (MM1 and VV2) cases showed reduced level of t-PrP in both subtypes but significantly more in CJD-MM1 subtype and decreased expressional regulation of $\mathrm{t}-\mathrm{PrP}$ in CSF correlate brain at mRNA level [45-47]. Recent advancement and amalgamation of new techniques lead to improve the detection system by using CSF samples from Prion disease patients, showed sensitivity and specificity for seeding activity by using RT-QuIC in comparision to age matched healthy and nondemented controls [27,48-50]. Taken together, these studies indicate that PrP levels in CSF are on average lower level in individuals with prion disease. However, one study in sheep model reported that there is no significant difference in between CSF t-PrP expression as compared to controls [51]. In conclusion, $t-P r P$ expression could be a specific marker in symptomatic prion disease patients than in controls [44-47].

\section{Exosomal Biomarkers}

Exosomes are nanoparticles, secreted into the extracellular environment during the transportation of vesicular factors [52] and are reported as carriers for $\mathrm{PrP}^{\mathrm{c}}$ and $\mathrm{PrP}^{\mathrm{sc}}$ [53] For the diagnosis of prion disease, recently a group showed specific exosomal miRNA signature in prion-infected neuronal cells that can be utilized for specific diagnostic pattern. This signature consists of significant increases in let-7 b, let-7i, miR-128 a, miR21, miR-222, miR-29 b, miR-342-3 p and miR-424 with decreased miR-146 [54]. Previous studies have also reported miRNA changes associated with exosomes detected in the brain of terminally infected mouse and primate models of prion disease, and sporadic CJD samples [55,56] suggesting exosomal markers as a novel biomarkers for prion diseases and could possibly be therapeutic approaches in later stages.

\section{Blood Based Biomarkers}

The only possible confirmed tool for prion diagnosis was by postmortem brain tissue. But the need for early detection is still under consideration. Therefore, body fluids and blood could be used as an ante mortem test. The level of $\mathrm{PrP}^{\mathrm{Sc}}$ is below the detection threshold, so $\mathrm{PrP}^{\mathrm{sc}}$ enrichment needs to be an additional step [57-59]. The major issue in blood detection system is high $\mathrm{PrP}^{\mathrm{C}}$ background and extremely small quantity of prions, consequently, specificity and sensitivity is an essential markup for the establishment of a blood test.

A number of studies have identified differential regulation of a handful of proteins in the blood of patients with CJD. One study has reported elevated levels of the $S-100 \beta$ protein and another, an increase in cystatin C levels [42]. Another study found elevated levels of heart fatty acid binding protein (H-FABP) in the serum of patients with CJD [60]. Fatty acid binding proteins are located within the cell and are responsible for the shuttling of fatty acids in the cytosol and are released from the cell in response to cell damage [60]. However, the elevated levels of heart fatty acid binding protein (H-FABP) have also been observed in Alzheimer disease, acute myocardial infarctions, and in stroke patients, implying that this is not a specific prion disease biomarker. Furthermore, murine scrapie showed erythroid-related genes named as (KEL, GYPA) differentially regulated in the spleens of infected [61]. However, these genes were found to be expressed at highly variable levels between individuals, thus prevent their usefulness as accurate markers for diagnosis.

Specificity of individual markers require careful analysis, So use of combination of multiple biomarkers rather than one single biomarker would be prudent in order to reach higher sensitivity and specificity for diagnosis of Prion diseases.

\section{References}

1. Prusiner SB (1982) Novel proteinaceous infectious particles cause scrapie. Science 216: 136-144.

2. Baskakov IV, Aagaard C, Mehlhorn I, Wille H, Groth D, et al. (2000) Self-assembly of recombinant prion protein of 106 residues. Biochemistry 39: 2792-2804.

3. Baskakov IV, Legname G, Gryczynski Z, Prusiner SB (2004) The peculiar nature of unfolding of the human prion protein. Protein Sci 13: 586-595.

4. Legname G, Nguyen HO, Baskakov IV, Cohen FE, Dearmond SJ, et al. (2005) Strain-specified characteristics of mouse synthetic prions. Proc Natl Acad Sci U S A 102: 2168-2173

5. Li WW, Cai DF, Ren HM (2006) [Neurodegenerative conformational disease and its molecular bases]. Sheng Li Ke Xue Jin Zhan 37: 97-102.

6. Baldwin MA, Cohen FE, Prusiner SB (1995) Prion protein isoforms, a convergence of biological and structural investigations. J Biol Chem 270 19197-19200.

7. De Simone A, Zagari A, Derreumaux $P$ (2007) Structural and hydration properties of the partially unfolded states of the prion protein. Biophys $\mathrm{J} 93$ 1284-1292.

8. Silva CJ (2014) Applying the tools of chemistry (mass spectrometry and covalent modification by small molecule reagents) to the detection of prions and the study of their structure. Prion $8: 42-50$

9. Kosmac M, Koren S, Giachin G, Stoilova T, Gennaro R, et al.(2011) Epitope mapping of a $\operatorname{PrP}(\mathrm{Sc})$-specific monoclonal antibody: identification of a nove C-terminally truncated prion fragment, Mol Immunol 48: 746-750.

10. Notari S, Strammiello R, Capellari S, Giese A, Cescatti M, et al. (2008) Characterization of truncated forms of abnormal prion protein in CreutzfeldtJakob disease. J Biol Chem 283: 30557-30565. 
11. Scott MR, Groth D, Tatzelt J, Torchia M, Tremblay P, et al (1997) Propagation of prion strains through specific conformers of the prion protein, $\mathrm{J}$ Virol 71 9032-9044.

12. Zafar S, Asif AR, Ramljak S, Tahir W, Schmitz M, et al. (2014) Anchorless 23 230 PrPC interactomics for elucidation of PrPC protective role. Mol Neurobio 49: $1385-1399$

13. Zanusso G, Farinazzo A, Prelli F, Fiorini M, Gelati M, et al. (2004) Identification of distinct N-terminal truncated forms of prion protein in different CreutzfeldtJakob disease subtypes. J Biol Chem 279: 38936-38942.

14. Alexandrov PN, Dua P, Lukiw WJ (2014) Up-Regulation of miRNA-146a in Progressive, Age-Related Inflammatory Neurodegenerative Disorders of the Human CNS. Front Neurol 5: 181.

15. Gossner AG, Hopkins J (2015) The effect of $\operatorname{PrP}(\mathrm{Sc})$ accumulation on inflammatory gene expression within sheep peripheral lymphoid tissue. Vet Microbiol 181: 204-211

16. Hasebe R, Suzuki A, Yamasaki T, Horiuchi M (2014) Temporary upregulation of anti-inflammatory cytokine IL-13 expression in the brains of CD14 deficient mice in the early stage of prion infection. Biochem Biophys Res Commun 454: 125-130.

17. Hill JM, Clement C, Zhao Y, Lukiw WJ (2015) Induction of the pro-inflammatory NFkB-sensitive miRNA-146a by human neurotrophic viruses. Front Microbiol 6: 43.

18. Liu J, Zhao D, Liu C, Ding T, Yang L, et al. (2015) Prion protein participates in the protection of mice from lipopolysaccharide infection by regulating the inflammatory process. J Mol Neurosci 55: 279-287.

19. Kübler E, Oesch B, Raeber AJ (2003) Diagnosis of prion diseases. Br Med Bul 66: $267-279$

20. Schaller O, Fatzer R, Stack M, Clark J, Cooley W, et al. (1999) Validation of a western immunoblotting procedure for bovine $\operatorname{PrP}(\mathrm{Sc})$ detection and its use as a rapid surveillance method for the diagnosis of bovine spongiform encephalopathy (BSE), Acta Neuropathol. 98: 437-443.

21. Bockman JM, Kingsbury DT (1988) Immunological analysis of host and agent effects on Creutzfeldt-Jakob disease and scrapie prion proteins. J Virol 62 3120-3127.

22. Lukan A, Vranac T, Curin $\AA$ erbec V (2013) TSE diagnostics: recent advances in immunoassaying prions. Clin Dev Immunol 2013: 360604.

23. Paraf A (1998) An immunological approach to prion diseases. Med Hypotheses 50: $85-90$.

24. Grau-Rivera O, Sanchez-Valle R, Bargallo N, Llado A, Gaig C, et al. (2015) Sporadic MM2-thalamic + cortical Creutzfeldt-Jakob disease: Utility of diffusion tensor imaging in the detection of cortical involvement in vivo, Neuropathology.

25. Cheng K, Sloan A, Avery KM, Coulthart M, Carpenter M, et al. (2014) Exploring physical and chemical factors influencing the properties of recombinant prion protein and the real-time quaking-induced conversion (RT-QuIC) assay, PLoS One 9: e84812.

26. Cramm M, Schmitz M, Karch A, Mitrova E, Kuhn F, et al. (2015) Stability and Reproducibility Underscore Utility of RT-QuIC for Diagnosis of CreutzfeldtJakob Disease. Mol Neurobiol.

27. Orrú CD, Groveman BR, Hughson AG, Zanusso G, Coulthart MB, et al. (2015) Rapid and sensitive RT-QulC detection of human Creutzfeldt-Jakob disease using cerebrospinal fluid. MBio 6 .

28. Satoh K (2013) [CSF analysis of patients with prion disease by biomarkers and real-time qucking-induced conversion (RT-QUIC) method]. Rinsho Shinkeigaku 23: $1252-1254$

29. Blennow K, Johansson A, Zetterberg H (2005) Diagnostic value of 14-3-3beta immunoblot and T-tau/P-tau ratio in clinically suspected Creutzfeldt-Jakob disease. Int J Mol Med 16: 1147-1149

30. Green AJ, Thompson EJ, Stewart GE, Zeidler M, McKenzie JM, et al. (2001) Use of 14-3-3 and other brain-specific proteins in CSF in the diagnosis of variant Creutzfeldt-Jakob disease, J Neurol Neurosurg Psychiatry 70: 744-748.

31. Ladogana A, Sanchez-Juan P, Mitrova E, Green A, Cuadrado-Corrales N et al. (2009) Cerebrospinal fluid biomarkers in human genetic transmissible spongiform encephalopathies, J Neurol 256: 1620-1628.

32. Sanchez-Juan P, Green A, Ladogana A, Cuadrado-Corrales N, Saanchez-Valle $\mathrm{R}$, et al. (2006) CSF tests in the differential diagnosis of Creutzfeldt-Jakob disease, Neurology 67: 637-643.
33. Zerr I, Kallenberg K, Summers DM, Romero C Taratuto A et al. (2009) Updated clinical diagnostic criteria for sporadic Creutzfeldt-Jakob disease, Brain 132 2659-2668.

34. Zerr I, Pocchiari M, Collins S, Brandel JP, de Pedro CJ, et al. (2000) Analysis of EEG and CSF 14-3-3 proteins as aids to the diagnosis of Creutzfeldt-Jakob disease, Neurology 55: 811-815.

35. Skillback T, Rosen C, Asztely F, Mattsson N, Blennow K, (2014) Diagnostic performance of cerebrospinal fluid total tau and phosphorylated tau in Creutzfeldt-Jakob disease: results from the Swedish Mortality Registry, JAMA Neurol 71: 476-483.

36. Stoeck K, Sanchez-Juan P, Gawinecka J, Green A, Ladogana A, et al. (2012) Cerebrospinal fluid biomarker supported diagnosis of Creutzfeldt-Jakob disease and rapid dementias: a longitudinal multicentre study over 10 years, Brain 135: 3051-3061.

37. Cohen OS, Chapman J, Korczyn AD (2015) CSF tau correlates with CJD disease severity and cognitive decline. Acta Neurol Scand.

38. Beekes M, Thomzig A, Schulz-Schaeffer WJ, Burger R (2014) Is there a risk of prion-like disease transmission by Alzheimer- or Parkinson-associated protein particles? Acta Neuropathol 128: 463-476.

39. Meiner Z, Kahana E, Baitcher F, Korczyn AD, Chapman J, et al. (2011) Tau and 14-3-3 of genetic and sporadic Creutzfeldt-Jakob disease patients in Israel. J Neurol 258: 255-262.

40. Otto M, Esselmann H, Schulz-Shaeffer W, Neumann M, Schröter A, et al. (2000) Decreased beta-amyloid1-42 in cerebrospinal fluid of patients with Creutzfeldt-Jakob disease. Neurology 54: 1099-1102.

41. Otto M, Wiltfang J, Cepek L, Neumann M, Mollenhauer B, et al. (2002) Tau protein and 14-3-3 protein in the differential diagnosis of Creutzfeldt-Jakob disease. Neurology 58: 192-197.

42. Otto M, Wiltfang J, Schütz E, Zerr I, Otto A, et al. (1998) Diagnosis of CreutzfeldtJakob disease by measurement of $\mathrm{S} 100$ protein in serum: prospective casecontrol study. BMJ 316: 577-582.

43. Mollenhauer B, Cullen V, Kahn I, Krastins B, Outeiro TF,et al. (2008) Direct quantification of CSF alpha-synuclein by ELISA and first cross-sectional study in patients with neurodegeneration, Exp Neurol 213: 315-325.

44. Dorey A, Tholance Y, Vighetto A, Perret-Liaudet A, Lachman I, et al. (2015) Association of cerebrospinal fluid prion protein levels and the distinction between Alzheimer disease and Creutzfeldt-Jakob disease, JAMA Neurol. 72: 267-275.

45. Meyne F, Gloeckner SF, Ciesielczyk B, Heinemann U, Krasnianski A, et al. (2009) Total prion protein levels in the cerebrospinal fluid are reduced in patients with various neurological disorders. J Alzheimers Dis 17: 863-873.

46. Torres M, Cartier L, Matamala JM, Hernández N, Woehlbier U, et al. (2012) Altered Prion protein expression pattern in CSF as a biomarker for CreutzfeldtJakob disease. PLoS One 7: e36159.

47. Llorens F, Ansoleaga B, Garcia-Esparcia P, Zafar S, Grau-Rivera O4, et al. (2013) PrP mRNA and protein expression in brain and $\operatorname{PrP}(\mathrm{c})$ in CSF in Creutzfeldt-Jakob disease MM1 and VV2. Prion 7: 383-393.

48. Atarashi R, Satoh K, Sano K, Fuse T, Yamaguchi N, et al. (2011) Ultrasensitive human prion detection in cerebrospinal fluid by real-time quaking-induced conversion. Nat Med 17: 175-178.

49. Cramm M, Schmitz M, Karch A, Zafar S, Varges D, et al. (2015) Characteristic CSF prion seeding efficiency in humans with prion diseases. Mol Neurobiol 51: 396-405.

50. McGuire LI, Peden AH, Orrú CD, Wilham JM, Appleford NE, et al. (2012) Rea time quaking-induced conversion analysis of cerebrospinal fluid in sporadic Creutzfeldt-Jakob disease. Ann Neurol 72: 278-285.

51. Picard-Hagen N, Gayrard V, Viguié C, Moudjou M, Imbs C, et al. (2006) Prion protein in the cerebrospinal fluid of healthy and naturally scrapie-affected sheep. J Gen Virol 87: 3723-3727.

52. Properzi F, Logozzi M, Fais S (2013) Exosomes: the future of biomarkers in medicine. Biomark Med 7: 769-778.

53. Février B, Laude H, Raposo G, Vilette D (2005) Exosomes: carriers of prions? Med Sci (Paris) 21: 132-133.

54. Bellingham SA, Coleman BM, Hill AF (2012) Small RNA deep sequencing reveals a distinct miRNA signature released in exosomes from prion-infected neuronal cells. Nucleic Acids Res 40: 10937-10949. 
Citation: Zafar S, Younus N, Zerr I (2015) Novel Biomarkers and the Diagnosis of Prion Diseases. J Mol Biomarkers Diagn S8:011. doi:10.4172/21559929.S8-011

Page 4 of 6

55. Montag J, Hitt R, Opitz L, Schulz-Schaeffer WJ, Hunsmann G, et al. (2009) Upregulation of miRNA hsa-miR-342-3p in experimental and idiopathic prion disease. Mol Neurodegener 4: 36.

56. Saba R, Goodman CD, Huzarewich RL, Robertson C, Booth SA (2008) A miRNA signature of prion induced neurodegeneration. PLoS One 3: e3652.

57. Bannach O, Reinartz E, Henke F, Dreßen F, Oelschlegel A, et al. (2013) Analysis of prion protein aggregates in blood and brain from pre-clinical and clinical BSE cases. Vet Microbiol 166: 102-108.

58. Chang B, Cheng X, Yin S, Pan T, Zhang H, et al. (2007) Test for detection of disease-associated prion aggregate in the blood of infected but asymptomatic animals, Clin Vaccine Immunol 14: 36-43.

59. Tattum MH, Jones S, Pal S, Collinge J, Jackson GS (2010) Discrimination between prion-infected and normal blood samples by protein misfolding cyclic amplification, Transfusion 50: 996-1002.

60. Guillaume E, Zimmermann C, Burkhard PR, Hochstrasser DF, Sanchez JC (2003) A potential cerebrospinal fluid and plasmatic marker for the diagnosis of Creutzfeldt-Jakob disease. Proteomics 3: 1495-1499.

61. Brown AR, Blanco AR, Miele G, Hawkins SA, Hopkins J, et al. (2007) Differential expression of erythroid genes in prion disease. Biochem Biophys Res Commun 364: 366-371.
This article was originally published in a special issue, Potential Biomarkers and Therapeutic Targets in Cancer Stem Cells handled by Editor(s). Dr. Murielle Mimeault, University of Nebraska Medical Center, USA 